\title{
Knowledge and care seeking practices for ear infections among parents of under five children in Kigali, Rwanda: a cross-sectional study
}

Kaitesi Batamuliza Mukara ${ }^{*}$, Peter Waiswa², Richard Lilford ${ }^{3}$ and Debara Lyn Tucci ${ }^{4}$

\begin{abstract}
Background: Infections affecting the middle ear are a common childhood occurrence. Some cases may present with ear discharge through a tympanic membrane perforation which may heal spontaneously. However, up to 5\% or more cases of those affected have persistent ear discharge. A number of barriers contribute towards delayed presentation at health facilities for treatment of ear infections. We conducted a study to evaluate parents' and caregivers' knowledge and care seeking practices for ear infections in children under five in Gasabo district in Kigali, Rwanda.
\end{abstract}

Methods: Parents/guardians ( $n=810$ ) were interviewed using a structured questionnaire to elicit their knowledge of ear infections in children under five and their attitude to seeking care for their children.

Results: The mean age of the respondents was 31.27 years ( $S D=7.88$, range 17-83). Considering an average of knowledge parameters which included causes, symptoms, prevention, treatment and consequences of ear infections, we found that $76.6 \%$ (622) of respondents were knowledgeable about ear infections. We defined a positive practice as seeking medical treatment (community health workers or health facility) and this was found in $89.1 \%$ (722) respondents. Correlating knowledge with choice of seeking treatment, respondents were 33\% less likely to practice medical pluralism $(\mathrm{OR}=0.33, \mathrm{Cl} 0.11-0.97, P=0.043)$ if they were familiar with infections. Moreover, urban dweller were 1.7 times more likely to know ear infections compared to rural dwellers $(\mathrm{OR}=1.70$, Cl 1.22-2.38, $P=0.002$ ).

Conclusion: The majority of respondents had good knowledge and positive attitudes and practices about ear infection. However, medical pluralism was common. There is need to improve the community's awareness and access to primary health care facilities for the care of ear infections especially in rural areas of Rwanda.

Keywords: Ear infections, Parents, Knowledge, Care seeking, Under five

\section{Background}

Infections affecting the middle ear are a diverse entity and a common childhood occurrence [1-4]. Acute otitis media $(\mathrm{AOM})$ is an inflammation of the middle ear mucosa presenting acutely with symptoms of otalgia and fever [4]. These infections account for the majority

\footnotetext{
* Correspondence: kaibat@hotmail.com

${ }^{1}$ ENT department, College of medicine and health Sciences, University of Rwanda, and Health Policy, Planning and Management, Makerere University School of Public Health, Kampala, Uganda

Full list of author information is available at the end of the article
}

of antibiotic prescriptions in young children $[3,4]$. The trend of prescribing antibiotics for acute ear infections continues to grow. Guidelines for treatment of AOM have advocated a 'wait and see' [3], as up to $80 \%$ of those affected show spontaneous resolution [4]. By the 3rd birthday, $80 \%$ of children have had at least one episode of acute otitis media [5]. Some cases of acute ear infection may present with ear discharge through a tympanic membrane perforation. The perforation may heal spontaneously in 2-14 days [4]. However, up to $41 \%$ of cases have persistent ear discharge; chronic 
suppurative otitis media (CSOM) [6]. This disease entity also presents with symptoms of tinnitus, hearing loss and persistent discharge refractive to medical treatment usually implying cholesteatoma. Treatment is by antibiotic ear drops and surgery for repair of the persistent tympanic membrane perforation and treatment of complications. Complications are dire and include neck abscesses, mastoiditis, facial nerve paralysis, labyrinthitis, lateral sinus thrombosis, meningitis and brain abscess $[4,7]$.

It is estimated that 330 million people have CSOM of which $60 \%$ have hearing loss; the majority of those affected are children [5]. Hearing loss adversely affects speech and language development and school performance in children [1, 8-10] and may eventually diminish prospects for gainful employment in adulthood. Moreover, 28,000 deaths are attributed to complications due to CSOM [7]. Data on ear infections in sub-Saharan Africa is limited. Published studies estimate CSOM among school going children at $1.6 \%$ reported in Tanzania [11] and 2.4\% in Kenya [12]. Babigambe (2005) reported a prevalence of $13.2 \%$ of CSOM among children aged 6-60 months living in a slum in Uganda [13].

Compelling evidence shows that the painless nature of CSOM renders it an overlooked condition [14-17]. For instance, in their study on prevalence of CSOM among children living in two slums of Dhaka City in Bangladesh, Kamal and Joarder (2014) found that a third of mothers of children examined and found to have CSOM were not aware that their child had this condition, and neither were they aware of the possible sequelae of untreated disease. Moreover, $60 \%$ of mothers were not familiar with CSOM nor its treatment and $47 \%$ of those who had CSOM, did not seek treatment for it [18].

Risky health seeking practices have been shown to significantly contribute towards an increase in otitis media [19]. In this paper, risky health seeking behaviour is defined as seeking curative services from a source other than that recognised by the Rwandan Health system to treat ear infections. This includes self-medicating with the use of herbs or any other alternative treatment. This definition is modified from the World Health Organisation's (WHO) working definition [20].

Optimal health seeking behaviour often depends on accessibility of health facilities coupled with knowledge and understanding of the benefit of modern medical treatment as opposed to local customs and beliefs [21-23]. Regarding use of traditional medicine, the WHO states that "rampant poverty is the prime cause for use, misuse and abuse of traditional medicine" [20]. Cultural beliefs could supersede education even among people with high literacy levels living in regions with strong cultural beliefs and practices, thus resulting in unhealthy care seeking practices [24].
Unpublished clinical data in Rwanda shows a high prevalence of ear infections in 2013. Up to $21 \%$ of patients seen in the ENT department at a referral hospital were diagnosed with ear infections, among whom were young adults who report having infections since childhood. Not only have clinicians noticed delays in presentation for those seeking treatment, but also noted reports of patients using traditional medicine for ear infections regardless of high access to medical insurance. Against this background, we conducted this study to determine the extent of knowledge and care seeking practices of parents and care givers for ear infections in children under 5.

\section{Methods}

Study design, setting and population

This was a community based study conducted in Gasabo district, one of the 3 districts of Kigali City with a population of 530,907 inhabitants (national census, 2012) and a population density of 1237 persons per square kilometre. It has both rural and urban settlements with 486 villages, 229 of which are rural while 257 are urban [25]. This district is home to one Private referral hospital which offers ENT services among others as well as 3 district hospitals, 17 health centres and 20 functional health posts. According to Integrated Household Living Conditions Survey (EICV3) of 2010/11, the mean transit time by foot to a health facility in Gasabo district is $43.6 \mathrm{~min}$ [26]. Each village has $100-150$ households and is supervised by 2 Community Health Workers (CHW) called cell coordinators, assisted by 1 assistant cell coordinator.

\section{Data collection}

Using random tables, we sampled 30 villages. CHWs provided a list of households with children aged below 5 years in the sampled villages from which 27 households within each village and an extra 3 households for replacement were sampled. One child from an eligible household was selected using Kish table.

The set exclusion criteria was parents who refused to consent to participate in the study or who refused to give consent for their children to participate. However, no respondent was excluded. A total of 810 parents or guardians were interviewed and 810 children of these parents examined.

We collected data in March 2016. Experienced research assistants carried out data collection while two trained medical students in their ENT clerkship examined the children. We collected data regarding demographics, household characteristics and assets, knowledge, perceptions and care practices of the parents or guardians regarding ear infections. Additional file 1 shows the questionnaire used for data collection. 


\section{Quality control and ethics}

Before starting data collection, we held a 1 day training of research assistants where they were familiarised with the study, the questionnaire and data collection procedure. A pre-test session was conducted in a different district of Rwanda and changes incorporated into the pre-designed questionnaire. Our study proposal was submitted and approved by both the College of Medicine and Health Sciences Research Ethics Committee of the University of Rwanda (approval notice: No. 355/CMHS IRB/2015) and the Makerere University School of Public Health Higher Degree Research and Ethics Committee (approval date: 07th December 2015). Parents or guardians with children under 5 in their household provided written consent availed to them both in Kinyarwanda and English to participate in the study.

\section{Data analysis}

We entered data using CSpro 6.2 software after which we performed data cleaning aided by the same software. We used STATA 13.0 for statistical analysis. Given the wide range in the age of respondents, we classified the age into groups with 15 years class interval as follows $\leq 30,31-45,46-60$ and $>60$. Although this last group includes respondents aged 61-83 years, there were only 7 respondents and this was considered a single group.

Knowledge about ear infections and care seeking practices were derived as frequencies and proportions of the responses obtained. Knowledge was subdivided into causes, symptoms, prevention, treatment and consequences of ear infections. The following responses were considered causes of ear infections: poor hygiene, wetting the ears, wax, foreign body and/or microbes. Ear discharge, hearing loss and pain are the cardinal symptoms of ear infections. Respondents who knew 2 of the 3 or any other symptoms were considered knowledgeable of symptoms. Prevention and treatment parameters were rated as 'yes' or 'no' and respondents who reported 'yes' were considered knowledgeable. Respondents who reported hearing loss, persistence of disease, extension into adjacent structures and death as consequences of hearing loss were considered knowledgeable.

We defined a positive practice as seeking medical treatment (CHW or health facility) while positive attitude was derived from responses for choice for treatment seeking and the reason for seeking alternative treatment. Respondents who reported 'not being worried', 'no need for treatment', and 'incurable' were categorised as negative attitude. Moreover choice for information seeking ( $\mathrm{CHW}$, health professional) was categorised as positive attitude. To build a knowledge, attitude and practices model, a sum average of each of the responses for each parameter was computed. Additional file 1 gives details of positive and negative ratings for knowledge, attitude and practices.
Socioeconomic status (SES) was derived using Principal Component analysis computed using STATA. We weighted variables of household size and occupancy, source of water supply, types of flooring materials, sanitation facilities and assets. The mean SES was computed and categorised in to Low, Middle and High.

Chi square test and logistic regression analysis were used to derive associations between knowledge of the parents or guardians, SES, residence (urban or rural) and their care seeking practices. The level of significance was set at $p<0.05$.

\section{Results}

We obtained data for 810 respondents whose results we present. Results from the examination of children will be presented in a subsequent paper.

\section{Parents'/guardians' characteristics}

The majority of respondents were female; 96\% (777). The mean age was 31.27 years $(\mathrm{SD}=7.88$, range $17-83$ ). A higher proportion of eligible parents took part in the study in urban areas compared to rural areas, accounting for 53\% (432) of the study sample. Forty-seven percent (383) of respondents fell in the low SES while 12\% (95) were in the high SES category. Fifty eight percent (465) had completed primary school education. More details are shown in Table 1 below.

\section{Knowledge and perceptions of ear infections}

Sixty-nine percent (561) said they were aware of ear infections, $88.4 \%$ (716) said they could be treated while $67.4 \%$ (546) said they could actually be prevented. Ear

Table 1 Socio-demographic characteristics of the respondents

\begin{tabular}{llll}
\hline Characteristic & & Frequency $(n=810)$ & Percent \\
\hline Gender & Males & 33 & 4 \\
& Females & 777 & 96 \\
Age group & $\leq 30$ & 429 & 52.9 \\
& $31-45$ & 346 & 42.7 \\
& $46-60$ & 28 & 3.5 \\
Average age & $>60$ & 7 & 0.9 \\
Residence & 31.27 years & & \\
& Rural & 378 & 46.7 \\
Level of education & Urban & 432 & 53.3 \\
& None & 50 & 6.2 \\
& Primary & 465 & 57.5 \\
& Secondary & 220 & 27.2 \\
& Vocational & 74 & 9.1 \\
Socioeconomic status & Low & 383 & 47.3 \\
& Middle & 332 & 41 \\
& High & 95 & 11.7 \\
\hline
\end{tabular}


infections were perceived to be caused by poor hygiene in $50.4 \%$ (408) of respondents and water entering the ear in $27 \%$ (219).

Hearing loss was the most common consequence of ear infections. This was reported by $94 \%$ (764) of respondents. Other consequences included poor performance in school reported by $26 \%$ (212), persistence of the disease, $14 \%$ (115), extension of disease to other organs, 13\% (106) and death 7\% (70). In contrast, 3\% (25) respondents said that ear infections have no consequences.

Table 2 above gives details on knowledge among respondents. We computed the average knowledge of respondents considering all knowledge parameters and found that $76.6 \%$ (622) of respondents were knowledgeable about ear infections. Moreover, 47\% (381) and 8.5\% (69) respondents knew two symptoms or three or more symptoms of ear infections respectively.

Using bivariate and multivariate analysis, there was no statistically significant difference in knowledge when we compared age groups, level of education or socioeconomic status. However, rural dwellers were 1.7 times more likely to have knowledge about ear infections compared to urban dwellers both on bivariate and multivariate analysis as shown in Table 3 below. While respondents were a third of times less likely to practice medical pluralism if they knew about ear infections on bivariate analysis, this was not significant at multivariate analysis.

\section{Attitudes towards ear infections}

A positive attitude was found in $79.6 \%$ (645) respondents. This entailed averaged evaluation of the reasons for their reported choice of treatment seeking, their rating of services provided by the health system as well as the source of information.

Table 2 Knowledge of respondents on ear infections

\begin{tabular}{llll}
\hline & & Frequency & Percent \\
\hline Knowledge of symptoms of & None & 61 & 7.5 \\
ear infections & 1 symptom & 299 & 36.9 \\
& 2 symptoms & 381 & 47.0 \\
& $\geq 3$ symptoms & 69 & 8.5 \\
Knowledge about prevention & Yes & 546 & 67.4 \\
& No & 264 & 32.6 \\
Knowledge about treatment & Yes & 716 & 88.4 \\
& No & 94 & 11.6 \\
Knowledge of causes of ear & Yes & 525 & 64.8 \\
infections & No & 285 & 35.2 \\
Knowledge about consequences & Yes & 789 & 97.4 \\
of infections & No & 21 & 2.6 \\
\hline
\end{tabular}

Respondents in the 31-45 age range were 50\% less likely to have negative attitudes compared to other age groups. Similarly, respondents with secondary education or higher and respondents from middle socioeconomic status were less likely to have a negative attitude towards ear infections. Respondents with a positive attitude were 1 in 5 times less likely to seek treatment at both modern and traditional healers compared to those with a negative attitude. These results were significant both on bivariate and multivariate analysis as shown in Table 4 below.

\section{Care seeking practices with regards to ear infections}

Practices were established considering where parents sought information and treatment. Positive practices was found in $89.1 \%$ (722) of respondents.

While as $96 \%$ (780) of respondents would seek treatment from a health facility, 19\% (153) would seek help from a traditional healer. The main reason for seeking traditional treatment was poverty (low affordability) 66\% (538), ignorance and lack of knowledge in 62\% (504) and lack of a health insurance $41 \%$ (333). Community health workers and health professionals were the preferred source of health information for $77 \%$ (621) and 60\% (452) respondents respectively. Table 5 gives further detail.

Urban dwellers were almost 2 times more likely than rural dwellers to have health enhancing practices for ear infections $(\mathrm{OR}=1.85$, CI 1.18-2.90, $P=0.008)$. Comparing education with practices, we found that while respondents with secondary and higher education were twice likely to have positive practices, $(\mathrm{OR}=2.08$, CI $0.89-4.87$, $P=0.091$ ), respondents with vocational education were almost 8 times more likely to have positive practices $(\mathrm{OR}=7.90$, CI 1.62-38.34, $P=0.010)$. Table 6 below elaborates these findings further.

\section{Discussion}

In this study which assessed knowledge and care seeking practices of parents of under-five children with ear infections, we found that the majority $(76.6 \%)$ of respondents were knowledgeable about ear infections while $89.1 \%$ had positive care seeking practices. We found no relationship between age group of parent and knowledge of ear infections nor care seeking practices. However, parents in the age range of 31-45 years were less likely to have negative attitudes to healthy care seeking compared to other age groups. We found no study looking at the influence of parental age on care seeking practices to compare with our results. Those who practiced medical pluralism or sought traditional treatment attributed it to poverty (low affordability) in $66 \%$ while $62 \%$ and $41 \%$ cited ignorance (lack of knowledge) and lack of a health insurance respectively. These findings are similar to 
Table 3 Knowledge of ear infections

\begin{tabular}{|c|c|c|c|c|}
\hline & \multicolumn{4}{|c|}{ Knowledge of ear infections } \\
\hline & Crude OR (Cl) & $P$-value & Adjusted OR (Cl) & $P$-value \\
\hline \multicolumn{5}{|l|}{ Age group } \\
\hline$\leq 30$ & 1 & & 1 & \\
\hline $31-45$ & $0.8(0.57-1.12)$ & 0.192 & $0.89(0.62-1.26)$ & 0.511 \\
\hline $46-60$ & $2(0.91-4.40)$ & 0.086 & $2.26(0.10-5.12)$ & 0.064 \\
\hline$>60$ & $0.51(0.61-4.32)$ & 0.54 & $0.57(0.06-4.92)$ & 0.638 \\
\hline \multicolumn{5}{|l|}{ Residence } \\
\hline Rural & 1 & & 1 & \\
\hline Urban & $1.7(1.22-2.38)$ & $0.002^{*}$ & $1.69(1.17-2.44)$ & $0.003^{* *}$ \\
\hline \multicolumn{5}{|l|}{ Level of education } \\
\hline None & 1 & & 1 & \\
\hline Primary education & $1.48(0.67-3.24)$ & 0.333 & $1.55(0.68-3.53)$ & 0.228 \\
\hline Secondary \& higher & $1.92(0.85-4.34)$ & 0.116 & $1.61(0.67-3.84)$ & 0.24 \\
\hline Vocational education & $1.69(0.67-4.25)$ & 0.267 & $1.31(.48-3.60)$ & 0.483 \\
\hline \multicolumn{5}{|l|}{ Socioeconomic status } \\
\hline Low & 1 & & 1 & \\
\hline Middle & $1.35(0.95-1.91)$ & 0.095 & $1.25(0.87-1.80)$ & 0.254 \\
\hline High & $1.23(0.72-2.09)$ & 0.446 & $1.13(0.63-2.01)$ & 0.783 \\
\hline \multicolumn{5}{|c|}{ Where they would seek treatment } \\
\hline None & 1 & & 1 & \\
\hline Modern treatment & $0.47(0.18-1.24)$ & 0.126 & $0.45(0.17-1.24)$ & 0.123 \\
\hline Traditional medicine & $0.62(0.22-1.77)$ & 0.371 & $0.71(0.24-2.10)$ & 0.533 \\
\hline Medical pluralism & $0.33(0.11-0.97)$ & $0.043^{*}$ & $0.35(0.11-1.04)$ & 0.06 \\
\hline
\end{tabular}

*significant at bivariate analysis, ${ }^{*}$ significant at multivariate analysis

those of Srikanth in their study on knowledge, attitudes and practices with respect to $\mathrm{OM}$ in a rural community in India [22], and also Adeyemo [27] in Nigeria where they found low overall knowledge of otitis media. Only $47 \%$ of respondents could identify 2 symptoms of ear infections. Ear discharge, hearing loss and pain were the most common symptoms of ear infections reported, while awareness of other symptoms was low. Pain is a key symptom in acute otitis media $[2,28]$ while ear discharge is an integral pointer to CSOM [2, 29]. This study looked at ear infections globally and the wide range of symptoms is explained by the nature of ear infections. However, responses given depict more knowledge and awareness of CSOM as compared to acute otitis media.

We found a significant difference in knowledge of ear infections among parents living in rural areas compared to urban areas. Parents in rural areas were more likely to seek traditional treatment for ear infections. Our respondents were more likely to seek modern treatment if they were familiar with ear infections, if they had attained secondary education and beyond and if they lived in an urban setting. Consequently, children from rural areas are at a higher risk of delayed presentation or practicing medical pluralism and developing complications. This is alluded to by Shaheen and colleagues who found treatment seeking in favour of traditional medicine [14]. To overcome this, factors found to result in risky healthseeking behaviour in this study like those found in other studies, which include unaffordable health cost, poor point of care service delivery, distance barriers [22, 30], shortage of medicine in health facilities, and lack of involvement of male parents in child care [30] should be addressed. Findings from a study in Nigeria showed that strong traditional beliefs and practices were more important than level of education in making choices on health. Therefore, health promotion activities can go a long way to foster good health seeking practices.

Respondents who sought traditional treatment attributed this to poverty, lack of awareness and lack of insurance. This finding underscores that CSOM is a disease of poverty [31, 32]. Poverty was associated with inability to pay for services as well as failing to meet transport costs even if the child had medical insurance. Currently, 
Table 4 Attitude towards ear infections

\begin{tabular}{|c|c|c|c|c|}
\hline & \multicolumn{4}{|c|}{ Attitudes to ear infections } \\
\hline & $\mathrm{OR}(\mathrm{Cl})$ & P-value & Adjusted OR (Cl) & $P$-value \\
\hline \multicolumn{5}{|l|}{ Age group } \\
\hline$\leq 30$ & 1 & & 1 & \\
\hline $31-45$ & $0.59(0.41-0.84)$ & $0.004^{*}$ & $0.54(0.37-.79)$ & $0.001^{* *}$ \\
\hline $46-60$ & $1.27(0.54-2.96)$ & 0.586 & $1.19(0.49-2.87)$ & 0.704 \\
\hline$>60$ & 1 & & 1 & \\
\hline \multicolumn{5}{|l|}{ Residence } \\
\hline Rural & 1 & & 1 & \\
\hline Urban & $0.91(0.65-1.28)$ & 0.6 & $1.07(0.73-1.61)$ & 0.677 \\
\hline \multicolumn{5}{|l|}{ Level of education } \\
\hline None & 1 & & 1 & \\
\hline Primary education & $1.02(0.51-2.01)$ & 0.962 & $0.10(0.49-2.09)$ & 0.965 \\
\hline Secondary \& higher & $0.44(0.21-0.95)$ & $0.037^{*}$ & $0.41(0.18-0.94)$ & $0.034^{* *}$ \\
\hline Vocational education & $0.67(0.28-1.63)$ & 0.383 & $0.72(0.27-1.94)$ & 0.516 \\
\hline \multicolumn{5}{|l|}{ Socioeconomic status } \\
\hline Low & 1 & & 1 & \\
\hline Middle & $0.56(0.38-0.81)$ & $0.002^{*}$ & $0.59(0.39-0.87)$ & $0.009^{* *}$ \\
\hline High & $0.65(0.37-1.16)$ & 0.143 & $0.80(0.42-1.51)$ & 0.487 \\
\hline \multicolumn{5}{|c|}{ Where they would seek treatment } \\
\hline None & 1 & & & \\
\hline Modern treatment & $0.58(0.21-1.58)$ & 0.286 & $0.39(0.14-1.13)$ & 0.082 \\
\hline Traditional medicine & $0.45(0.15-1.38)$ & 0.163 & $0.12(0.09-0.89)$ & $0.031^{* *}$ \\
\hline Medical pluralism & $0.18(0.05-0.59)$ & $0.005^{*}$ & $0.12(0.04-0.43)$ & $0.001^{* *}$ \\
\hline
\end{tabular}

${ }^{*}$ significant at bivariate analysis, ${ }^{*}$ *significant at multivariate analysis

adherence to the Community Based Health Insurance is 91\% having increased steadily since being rolled out in 2000 [33]. Consequently more people are able to visit health facilities resulting in long queues that may be a discouragement to patients especially farmers. Holding a Community Based Health Insurance did not therefore preclude traditional medicine as an option for care seeking among our respondents. Health communication and education drives are necessary to help parents understand the nature of ear infections and their treatment to enhance care seeking practices.

The varying attitude and willingness to seek medical treatment seen among our respondents might be due to low level of knowledge, poverty, unsatisfactory service provision at point of first contact and delays in referral health system factors such as long queues. This finding is reported in other studies [30, 34]. Markedly, up to $85 \%$ of patients with CSOM in a study in Bangladesh preferred to seek over the counter treatment from untrained local village drug vendors instead of seeking help from qualified staff [14]. Overall, the social context may have the upper hand in determining care seeking behaviour. Participatory planning and provision of services involving beneficiaries as well as improvement of services could help increase utilisation of services thus increase awareness, prevention and treatment of ear infections.

The policy and practice implications of these findings include re-thinking inclusion of ear and hearing care among the attributes of CHWs. The WHO has outlined primary ear and hearing care manuals which can be tailored to a local context [35]. The manuals can help to address the lack of awareness and offer guidance to the scope of practice of era and hearing care at the different levels. This will increase awareness among CHWs which will in turn modify care seeking practices among parents. There is need to improve available ear care services at the primary health care facilities to make them the preferred choice of source of care.

\section{Study limitations}

This study has several strengths but also some limitations. It is the first of its kind to be conducted in Rwanda. In addition, it was a large study that included both a rural and urban context meaning that the findings could be representative of Rwanda and similar 
Table 5 Care seeking practices

\begin{tabular}{|c|c|c|c|}
\hline & & Frequency & Percent \\
\hline \multirow[t]{5}{*}{ Where they seek treatment } & Health facility ${ }^{\mathrm{a}}$ & 780 & 96 \\
\hline & Traditional medicine ${ }^{a}$ & 153 & 19 \\
\hline & Community health worker & 68 & 8 \\
\hline & Self-medication & 17 & 2 \\
\hline & I would not seek treatment & 8 & 1 \\
\hline \multirow{6}{*}{$\begin{array}{l}\text { Why they seek alternative } \\
\text { therapy }\end{array}$} & Poverty $^{\mathrm{a}}$ & 538 & 66 \\
\hline & Ignorance ${ }^{a}$ & 504 & 62 \\
\hline & No health insurance ${ }^{a}$ & 333 & 41 \\
\hline & Not worried about it & 23 & 3 \\
\hline & No need, its incurable & 17 & 2 \\
\hline & Others $^{a}$ & 86 & 11 \\
\hline \multirow[t]{5}{*}{ Source of information } & Community Health worker ${ }^{\mathrm{a}}$ & 621 & 77 \\
\hline & Health professional ${ }^{a}$ & 452 & 60 \\
\hline & Family or neighbours & 44 & 5 \\
\hline & Others & 28 & 4 \\
\hline & I don't need it & 8 & 1 \\
\hline \multirow{6}{*}{$\begin{array}{l}\text { Consequences of } \\
\text { infections }\end{array}$} & Hearing loss ${ }^{\mathrm{a}}$ & 764 & 94 \\
\hline & Persistence of the disease $\mathrm{e}^{\mathrm{a}}$ & 115 & 14 \\
\hline & Extension to other organs ${ }^{a}$ & 106 & 13 \\
\hline & Death & 70 & 7 \\
\hline & None & 25 & 3 \\
\hline & Others & 16 & 2 \\
\hline
\end{tabular}

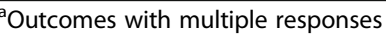

settings elsewhere. The limitations include the fact that the questionnaire was formulated in English then translated into Kinyarwanda and back. However, Kinyarwanda lack terminologies equivalent to those in English causing some responses to be missed or generalized. For instance, ear discharge is synonymous with CSOM in Kinyarwanda yet that is not the case in English nor in this study. In addition, dichotomising knowledge maybe crude since this could have multiple connotations.

\section{Conclusions}

The majority of respondents had good knowledge and positive attitudes and practices about ear infection. The preferred point for care seeking is heavily dependent upon knowledge of ear infections and less on age of the parent, gender and SES. Parents in rural settings are more likely to practice medical pluralism. While consequences of ear infections are known, parents still cling to risky health seeking practices for their children. More effort should be put in improving health service accessibility and delivery since this is a barrier to health care seeking practices. Medical professionals and $\mathrm{CHW}$ should be educated on ear infection since this is the preferred source of information. More research is required to assess the impact of training and health promotion on knowledge of parents and care seeking practices for ear infections.

Table 6 Practices for ear infections

\begin{tabular}{|c|c|c|c|c|}
\hline & \multicolumn{4}{|c|}{ Practices of ear infections } \\
\hline & $\mathrm{OR}(\mathrm{Cl})$ & $P$ value & Adjusted OR (Cl) & $P$-value \\
\hline \multicolumn{5}{|l|}{ Age group } \\
\hline$\leq 30$ & 1 & & 1 & \\
\hline $31-45$ & $0.74(0.47-1.17)$ & 0.202 & $0.80(0.42-1.56)$ & 0.519 \\
\hline $46-60$ & $0.63(0.21-1.92)$ & 0.42 & $0.17(0.22-6.25)$ & 0.855 \\
\hline$>60$ & Not computed & & & \\
\hline \multicolumn{5}{|l|}{ Residence } \\
\hline Rural & 1 & & 1 & \\
\hline Urban & $1.85(1.18-2.90)$ & $0.008^{*}$ & & \\
\hline \multicolumn{5}{|l|}{ Level of education } \\
\hline None & 1 & & 1 & \\
\hline Primary education & $1.6(0.74-3.48)$ & 0.232 & $0.98(0.29-3.25)$ & 0.972 \\
\hline Secondary \& higher & $2.08(0.89-4.87)$ & 0.091 & $1.65(0.43-6.41)$ & 0.468 \\
\hline Vocational education & $7.9(1.62-38.34)$ & $0.01^{*}$ & 2.57(0.34-19.24) & 0.359 \\
\hline \multicolumn{5}{|l|}{ Socioeconomic status } \\
\hline Low & 1 & & 1 & \\
\hline Middle & $1.48(0.91-2.39)$ & 0.112 & $1.74(0.87-3.48)$ & 0.121 \\
\hline High & $1.4(0.67-2.97)$ & 0.377 & $1.70(0.50-5.77)$ & 0.394 \\
\hline
\end{tabular}

\footnotetext{
*significant at bivariate analysis
} 


\section{Additional files}

Additional file 1: Questionnaire designed specifically for this study and used to collect data. Gives details of criteria for ratings of knowledge, attitude and care seeking practices applied in our study. (DOCX 59 kb)

\section{Abbreviations}

AOM: Acute otitis media; CHW: Community Health Worker; CSOM: Chronic suppurative otitis media; ENT: Ear, Nose and Throat department;

SES: Socioeconomic status; WHO: World Health Organisation

\section{Acknowledgements}

Thanks to Mr. Ntambara Juvenal for his insight patience and guidance in data collection and data entry and Drs Kosuke, Hinda and Ndahindwa for guidance in data analysis. Many thanks to CARTA and all facilitators who in one way or another contributed to this work.

\section{Funding}

"This research was supported by the Consortium for Advanced Research Training in Africa (CARTA). CARTA is jointly led by the African Population and Health Research Center and the University of the Witwatersrand and funded by the Wellcome Trust (UK) (Grant No: 087547/Z/08/Z), the Department for International Development (DfID) under the Development Partnerships in Higher Education (DelPHE), the Carnegie Corporation of New York (Grant No: B 8606), the Ford Foundation (Grant No: 1100-0399), Google.Org (Grant No: 191994), Sida (Grant No: 54100029) and MacArthur Foundation Grant No: 10-95915-000-INP"

\section{Availability of data and materials}

The datasets used and analysed during the current study are available from the corresponding author on reasonable request.

\section{Authors' contributions}

All authors were involved in developing the study design and implementation. KBM collected and analysed data while PW, RL and DT provided overall supervision. KBM wrote the draft. PW, RL and DT reviewed the draft and approved the final manuscript. All authors read and approved the final manuscript.

\section{Ethics approval and consent to participate}

This study obtained approved by both the College of Medicine and Health Sciences Research Ethics Committee of the University of Rwanda (approval notice: No. 355/CMHS IRB/2015) and the Makerere University School of Public Health Higher Degree Research and Ethics Committee (approval date: 07th December 2015). All parents or guardians whose children were included in the study provided written consent in Kinyarwanda or English to participate in the study.

\section{Consent for publication}

Not applicable.

\section{Competing interests}

The authors declare that they have no competing interests.

\section{Publisher's Note}

Springer Nature remains neutral with regard to jurisdictional claims in published maps and institutional affiliations.

\section{Author details}

${ }^{1}$ ENT department, College of medicine and health Sciences, University of Rwanda, and Health Policy, Planning and Management, Makerere University School of Public Health, Kampala, Uganda. 'Department of Health Policy, Planning and Management, Makerere University School of Public Health, Uganda and Global Health Division, Karolinska Institutet, Stockholm, Sweden. ${ }^{3}$ Warwick Medical School, University of Warwick, Coventry, UK. ${ }^{4}$ Head and Neck Surgery \& Communication Sciences, Duke University, Durham, USA.
Received: 1 March 2017 Accepted: 28 September 2017

Published online: 10 October 2017

\section{References}

1. Yiengprugsawan V, Hogan A, Strazdins L. Longitudinal analysis of ear infection and hearing impairment: findings from 6-year prospective cohorts of Australian children. BMC Pediatr. 2013:13:28

2. Todberg $T$, et al. Incidence of otitis media in a contemporary Danish National Birth Cohort. PLoS One. 2014:9(12):e111732.

3. Barber $C$, et al. Acute otitis media in young children - what do parents say? Int J Pediatr Otorhinolaryngol. 2014;78(2):300-6.

4. Qureishi A, et al. Update on otitis media - prevention and treatment. Infect Drug Resist. 2014;7:15-24.

5. Monasta L, et al. Burden of disease caused by otitis media: systematic review and global estimates. PLoS One. 2012;7(4):e36226.

6. Macfadyen $\mathrm{C}$, et al. Topical quinolone vs. antiseptic for treating chronic suppurative otitis media: a randomized controlled trial. Tropical Med Int Health. 2005;10(2):190-7.

7. Acuin J, Chronic suppurative otitis media: burden of illness and management options. 2004.

8. Smith AW. WHO activities for prevention of deafness and hearing impairment in children. Scand Audiol Suppl. 2001;53:93-100.

9. Sanders $M$, et al. Estimated prevalence of hearing loss and provision of hearing services in Pacific Island nations. J Prim Health Care. 2015;7(1):5-15.

10. Baltussen R, Smith A. Cost-effectiveness of selected interventions for hearing impairment in Africa and Asia: a mathematical modelling approach. Int J Audiol. 2009;48(3):144-58.

11. Bastos I, et al. Middle ear disease and hearing impairment in northern Tanzania. A prevalence study of schoolchildren in the Moshi and Monduli districts. Int J Pediatr Otorhinolaryngol. 1995;32(1):1-12.

12. Smith AW, et al. Randomised controlled trial of treatment of chronic suppurative otitis media in Kenyan schoolchildren. Lancet. 1996;348(9035):1128-33.

13. Babigamba TE, Prevalence and types of chronic suppurative otitis media among children aged six months to five years in slum dwelling of Kamwokya-Kifumbira, Kampala district, in ENT department. 2005, Makerere University.

14. Shaheen MM, Raquib A, Ahmad SM. Chronic suppurative otitis media and its association with socio-econonic factors among rural primary school children of Bangladesh. Indian J Otolaryngol Head Neck Surg. 2012;64(1):36-41.

15. Orji F. A survey of the burden of management of chronic suppurative otitis media in a developing country. Ann Med Health Sci Res. 2013;3(3):598-612.

16. Ologe FE, Nwawolo CC. Prevalence of chronic suppurative otitis media (CSOM) among school children in a rural community in Nigeria. Niger Postgrad Med J. 2002:9(2):63-6.

17. Morris P. Chronic suppurative otitis media. BMJ Clin Evid. 2012;2012. p. 0507

18. Kamal N, Joarder AH. Prevalence of chronic suppurative otitis media among the children living in two selected slums of Dhaka City. Bangladesh Med Res Counc Bull. 2004;30:95-104.

19. Rupa V, Jacob A, Joseph A. Chronic suppurative otitis media: prevalence and practices among rural South Indian children. Int J Pediatr Otorhinolaryngol. 1999;48:217-24

20. World Health Organization, WHO traditional medicine strategy 2002-2005. Geneva: 2002.

21. Lasisi AO, Ajuwon JA. Beliefs and Perceptions of Ear, Nose and ThroatRelated Conditions among Residents of a Traditional community in Ibadan, Nigeria. Afr J Med Med Sci. 2001;31(1):49-52

22. Srikanth $\mathrm{S}$, et al. Knowledge, attitudes and practices with respect to risk factors for otitis media in a rural South Indian community. Int J Pediatr Otorhinolaryngol. 2009:73(10):1394-8.

23. Poole $\mathrm{N}$, et al. Knowledge, attitudes, beliefs and practices related to chronic suppurative otitis media and hearing impairment in Pokhara, Nepal. J Laryngol Otol. 2016;130(01):56-65.

24. Njoroge GN, Bussmann RW. Traditional management of ear, nose and throat (ENT) diseases in Central Kenya. J Ethnobiol Ethnomed. 2006;2(1):1.

25. National Institute of Statistics of Rwanda (NISR) and Ministry of Finance and Economic Planning (MINECOFIN), Fourth Population and Housing Census, Rwanda, 2012. Thematic report: Characteristics of households and housing. 2014.

26. National Institute of Statistics of Rwanda. The Third Integrated Household Living Conditions Survey (EICV 3) Main indicators report. Kigali: Ministry of Finance and Economic Planning; 2012. 
27. Adeyemo AA. Knowledge of caregivers on the risk factors of otitis media. Indian J Otol. 2012;18(4):184.

28. Curry MD, et al. Beliefs about and responses to childhood ear infections: a study of parents in eastern North Carolina. Soc Sci Med. 2002;54(8):1153-65.

29. Acuin J. Chronic suppurative otitis media. BMJ Clin Evid. 2007;2007. p. 0507.

30. Mbonye AK. Prevalence of Childhood IIInesses and Care-Seeking Practices in Rural Uganda. Sci World J. 2003;3:721-30.

31. Clarke S, et al. A study protocol for a cluster randomised trial for the prevention of chronic suppurative otitis media in children in Jumla, Nepal. BMC Ear Nose Throat Disord. 2015;15(1):4.

32. Li MG, et al. Is chronic suppurative otitis media a neglected tropical disease? PLoS Negl Trop Dis. 2015;9(3):e0003485.

33. Ministry of Health Rwanda. Third Health Sector Strategic Plan July 2012June 2018. Kigali: Ministry of Health; 2012.

34. Lasisi AO. Otolaryngological Practice in Developing Country: A Profile of Met and Unmet Needs. East Central Afr J Surg. 2008;13(2):101-4.

35. World Health Organization. Primary ear and hearing care training manuals. Geneva: World Health Organization; 2006.

Submit your next manuscript to BioMed Central and we will help you at every step:

- We accept pre-submission inquiries

- Our selector tool helps you to find the most relevant journal

- We provide round the clock customer support

- Convenient online submission

- Thorough peer review

- Inclusion in PubMed and all major indexing services

- Maximum visibility for your research

Submit your manuscript at www.biomedcentral.com/submit
Biomed Central 